\title{
MJN \\ NURSING EXPERIENCE OF HAJJ-MEDICAL WORKERS OF INDONESIA IN HANDLING EMERGENCY STATE OF KENDARI-HAJJ PILGRIMS
}

\author{
Eman Sulaiman*, Indah Winarni, Tina Handayani Nasution \\ Department of Emergency Nursing, Brawijaya University, Malang, Indonesia \\ *Corresponding Author's Email:emansoelaiman"17@yahoo.co.id
}

\begin{abstract}
The purpose of this research is to explore the meaning of nurses at a medical team of Indonesia Hajj regarding the experience in handling emergency state of Kendari-hajj pilgrims. The research approach is Interpretative Phenomenology. The participants consist of 3 males and 2 females. The sample was chosen based on purposive sampling technique. The inclusion criteria were based on nurses at a medical team of Indonesia hajj in charge of emergency state case of hajj-pilgrims. The data collections are done by in-depth interview, observation, and field note documentation. The findings found three themes: (1) treating the pilgrims as family, (2) facing unexpected condition at the holy land, and (3) facing burdening challenges in doing task to save the pilgrims.
\end{abstract}

Keywords: Nurses, Medical Team, Interpretative Phenomenology, Emergency State

\section{INTRODUCTION}

Million of Islam people around the world, anually go on pilgrimage called Hajj in Meka Saudi Arabia. The gathering of million pilgrims cause intense density, traffic, and extreme temperature which is the triggering factor of acute, emergency, chronic, and contagious health problems which cause rise in the rate of disease and death of the pilgrims (Ahmed, Arabi \& Memish, 2006).

Indonesia is a country with the highest numbers of Islam in the world. About $87.18 \%$ are Islam people (Pew Research Centre, 2011). It makes Indonesia to be the first ranked country with most Hajj-pilgrim of all the countries in the world. Profile of Indonesian pilgrims in last ten years seems not to be different significantly. Annually, rates of Indonesian Hajj pilgrims are about $60 \%$ compared to $67 \%$ of Hajj Pilgrims from other holy lands. This is categorized as high risk group which may endanger safety and health of Indonesian pilgrims during worshipping period. The rate of disease and death tends to fluctuate, however it is still considered high (Ministry of Health, 2017). Research by (Pane et al., 2013) found that $68 \%$ of death of pilgrims occur in Mecca and 24\% in Medinna.

Interview results of 5 nurses at a medical team of Indonesia Hajj in Kendari showed the causes of emergency state of the pilgrims are internal factors (age, inherited disease, educational level) and external factor (extreme temperature, density, geographical condition, and contangious disease). Any hindrance experienced during giving treatment during emergency state are due to limited numbers of nurses in the medical team of Indonesia hajj. For instance 2 nurses and 1 doctor provided service to 450 pilgrims with limited medical equipment, difficulty in access to get ambulance which may lead to hindered evacuation process. This research is expected to actually, investigate problems in depth and comprehensively or to detect the weaknesses influencing the role of nurses in a medical team of Indonesia hajj while handling emergency state treatment of Hajj pilgrims.

\section{METHODOLOGY}

This research used interpretive phenomenological approach with purposes to explore, understand, and 
interpret the role of the nurses at a medical team of Indonesia during hajj in handling emergency state of Kendari-Hajj pilgrims. Participant selection is done by using purposive sampling - a process of selection based on inclusive criteria of nurses at a medical team of Indonesia hajj in Kendari who have experience of handling emergency state condition of Hajj pilgrims. There are five participants reaching saturated data.

The data is collected through in-depth interview and data collection in the field. The interview guideline included open question related to working experience of the participants in handling Hajj-pilgrims with emergency state and interview is done at each working unit of the participant. All interview data are recorded and coded verbatimly, then it is analyzed by using Interpretative Phenomenological Analysis acording to Smith et al., (2009) following the stages: reading and reading verbatim data manytimes, underlining the words with potencies to arrive on themes, organizing emerging themes, detecting inter-relationship between theme, following the same pattern in other participants with the same procedures, detecting themes across participants, interpreting higher level by creating metaphors.

Data validity uses credibility criteria, to check in detail and the gained data is completed by repeatedly asking something that is unclear, seeking additional information comprehensively, and asking clarification when there is indistinct statement of the participants. Transferability is done by considering various sample of the data to get in depth variety of views and meaning of the data achieved from participants. Process of collecting data, analysis step, and reporting are done by involving senior researcher in qualitative field and all these activities are documented properly in the form of recording of interview, field notes, and verbatim transcript attachment and thematic analysis table on research report. Dependability is done by auditing all research process, included in analysis and writing research report. Confirmability is done by re-checking all data and the interpretation, including supporting literatures.

Ethical principle of this research is emphasized on ethical reliability issued by medical ethic comission of Haluoleo University, Kendari.

\section{RESULTS}

In the present study there are five participants selected as respondent nurses. The demograpphy of the participants were represented as in table 1 . These nurses were interviewed and their views were noted.

Table 1: Characteristics of the Participants (P)

\begin{tabular}{|c|c|c|c|c|c|c|c|c|}
\hline No. & Gender & Age & Education & Working Status & Unit of Duty & Skill/Training & Periode of duty & $\begin{array}{c}\text { Total of the } \\
\text { Pilgrims }\end{array}$ \\
\hline P1 & Male & 46 & $\begin{array}{l}\text { Under Degree of } \\
\text { Nursery }\end{array}$ & Civil Servant (CS) & Ambulance 118 & $\begin{array}{c}\text { Basic Training Cardiac Live } \\
\text { Support(BTCLS) }\end{array}$ & 2011 & 350 \\
\hline $\mathrm{P} 2$ & Female & 36 & Ners & $\mathrm{CS}$ & Intensive Care Unit & BTCLS & 2017 & 450 \\
\hline P3 & Male & 44 & $\begin{array}{l}\text { First Degree of } \\
\text { Nursery }\end{array}$ & $\mathrm{CS}$ & operating room & BTCLS & 2015 & 450 \\
\hline P4 & Female & 42 & $\begin{array}{l}\text { First Degree of } \\
\text { Nursery }\end{array}$ & $\mathrm{CS}$ & $\begin{array}{l}\text { Tuberculosis } \\
\text { Program }\end{array}$ & BTCLS & 2018 & 450 \\
\hline P5 & Male & 37 & Ners & CS & operating room & BTCLS & 2018 & 450 \\
\hline
\end{tabular}

This research results three themes. Theme (1) is treating the pilgrims as family, (2) staying to face unexpected condition in holy land, and (3) facing burdening challenges while saving life of the pilgrims.

\section{Theme : Treating the Pilgrims as Family}

This approach assumes the pilgrim as family to develop trust, intimacy, activeness, and transparency between pilgrims and participants while interacting health service and the most importantly is for quick and early identification of health status of the pilgrims.

\section{Sub theme : Recognizing the pilgrims to find out the causes of their emergency state}

The participants' efforts to find out further, more specific, and more detailed characteristics of pilgrims as information or basic data to arrange activity plan and to anticipate medical service. This is done by coordinating 
with regional/local health agency or the in-charge party to get temporal data of the pilgrims, to get direction of serial check up activities of the pilgrims at health care center and assigned hospitals and to coordinate with Regional/Province Religion Department to get consultation schedule along with the pilgrim's Hajj riutal. It is done by participant nurses to find out more information about the pilgrims' health status. As these participants' statements.

\section{Translated excerpt}

We have introduced ourselves to the pilgrim candidates. We did so to introduce ourselves as medical officers who will accompany them in holy land.(P3)

Another important thing, the health condition of the pilgrims'was checked directly, especially the high risk ones. (P3)

We know our patients with high risks. We collected the names, here in the group. Thus, it will reduce the load when there is acute patient but we do not know. But the treatment procedure will depend on patient's health record. $(P 1)$

\section{Withstanding in Facing Unexpected Condition in the Holy land}

Various unpredictable conditions and situations during Hajj can threaten health and safety of the pilgrims. The density of the pilgrims, traffic jam, extreme temperature, rocky and desert topography influence health and safety of the pilgrims.

\section{Sub theme: Concerns dealing High Risk Patients}

The characteristics of Indonesian pilgrims, especially from Kendari are still dominated by high risk pilgrims. Geographical condition of Saudi Arabia is difficult for them, the density of pilgrims, rites of worship are the concerns of the participant nurses regarding health and safety of the pilgrims. Overcrowding among pilgrims cause many of them to collapse. Extreme tempreature causes dehydration. Dust causes Breathing System Infection in the Upper region. All of them are in line with participants'statements.

Several pilgrims whom we have observed from Embarkasi get exhausted - specially the older ones - since they do not eat nor drink, thus they get dehydration.(P2)

We have listed each disease of pilgrim. We anticipate it. Just in case, if we need to stand by if something goes wrong. Thus, the high risk groups have already been observed. We prioritize them. We carefully look at them.(P3)

Total jam started from Wukuf. I just can leave all these to Allah and just can't always pray-hopefully no bad thing happens upon my group of pilgrims.(P3)

Seeing the condtiions of pilgrims, who are mostly are high risk group, as officers we worry about it because Hajj is pretty tough. Moreover the environmental condition is really hot and crowded.(P5)

Shoving causes many to collapsed. In Musdalifah, many patients collapse. We almost got panic but we tried to chill out. We cannot panic. Wee needed to keep calm.(P4)

\section{Sub theme: Concerns to Geographical Condition}

Saudi Arabia has extreme climatic condition, with temperature above $45^{\circ}$, large desert, and rocky mountain which is very difficult to bear for the Indonesian pilgrims. The geographical condition is very diferent to Indonesia, causing concerns of participants about health and safety of the pilgrims during Hajj. It is burdened by the numbers of high risk pilgrim. It is in line with participants' statements below.

The weather is hot; and there is sand directly below, the cooler cannot decrease the heat of the desert. The activity of Hajj is tiring.(Pl)

It was hot yesterday, $47^{\circ} \mathrm{C}$ to about $50^{\circ} \mathrm{C}$. It causes heatstroke, dehydration, upper breathing system infection due to heat. We were worried and concerned but we needed to keep calm while facing such emergency states both in airplane, in Armina or other places.(P2)

Arriving in Armina, the temperature reached $500 \mathrm{C}$. Then, when it was in Wukuf, all cooling devices were shut down. Many people were inside the tent so what we could bear the harsh weather condition. We worried about the high risk group.(P3)

\section{Sub theme: Anticipating Unexpected Occurrence}

Early anticipative effort is expected to improve 
health status and protect the pilgrims from disability or even death. As expressed by participants.

We have big luggage full of medicines because we do not know what we will face on the field for the sake of the pilgrim.(P3)

Instead of being bothered there, my friends and I divided tasks to bring portable equipment such as nebulla, digital pressure meter, and glucose content checker.(P5)

\section{Theme: Facing Burdening and Challenges while Saving Pilgrims}

Such human mobilisation makes Mecca a new civilized city. Level of traffict jam, density of pilgrims, and extreme weather with high temperature, $50^{\circ} \mathrm{C}$, dry and dusty situation makes the condition more prone towards adverse health status of Kendari pilgrims. Difficult geographical condition becomes burdening challenges for participants in giving aids to pilgrims. It is worsened by limitation of facility, access of evacuation. So the participant nurses find it difficult to take the pilgrims for treatment.

\section{Sub theme : Experiencing Burdening Challenges in Saving Pilgrims}

Emergency condition needs immediate treatment because fatal consequence entails the condition if it is not treated immediaely. Appropriate preparation and availability of facility support the accessibility to provide aid. Activities of the pilgrims i.e to move during Hajj becomes a challenge for participants in preparing many things so as to provide emergency aids for the pilgrims. Situations become worse when the participants are unable to to provide aid to the pilgrims due to limited equipment, insufficient working space and lack of supports from other participants.

So, when we went down there, we needed to carry the pilgrim because it was impossible for him to walk. I thought it was almost the end of him.(P3)

Ifelt sad to see the condition of weakening pilgrims who needed to wait longer to be taken. What else could we do? We had provided maximally.(P3)

When we helped them, we faced many difficulties. It could not be helped. As officer we must help the patient inspite of all the limitation, we needed to be ready anytime and anywhere.(P4)

\section{Breaching the Procedure to Help the Patient}

Breaching the procedure to help patient is an alternative for the participants when the situation is difficult, and resources are limited. Providing first aid during such emergency state is the best option. By using any available sources, skills, and owned abilities, the participant's creative ideas appeared to be useful in providing aids for the sake of the pilgrims. It is in line with participants' statements.

My patient is an old lady. She pooped on the place and could be moved anymore. I would like to put the infusion in the middle of the road. I climbed the tent, I tore the tent, I grabed the line of the infusion. I was warned by the worship guid. I said to him I would like to save mypatient.(Pl)

Ineeded to put the infusion in the tent inspite of the limitation because there is no place to hang it over.(P4)

So we specifically prepared to serve there. Actually, we asked other pilgrims to move away because many pilgrims gathering around would make the patient difficult to breath.(P5)

I worried at the first time while looking around, just in case, I could find any board or solid equipment such as bar or boxes for spalak. I searched for 5-10 minutes searching for them, I set up the splint, then we covered it by cotton, then the clamps. It was in emergency state case.(P5)

Moreover we are in overseas with limited things to do. $(P 1)$

\section{Sub theme : Experiencing Difficulties to Carry the Patient}

The density of the pilgrim caused traffic jam, more number of sick persons, limited access of transportation to go to the location and limited transportation are causes of hindrance to get and to find aid as well as to help the patients under emergency state conditoin. Such situations cannot be predicted and may occur anytime and anywhere and need immediate treatment. If it is late, it may lead to permanent disability or even threaten the patient's life. As stated by these participants.

I sought ambulance but the system insisted us to get into line. I was tensed, I said this is my patient, when he got aspiration due to his hemoptitis or his sianosis, who 
will take the responsibility? So I was on the road for almost $1 \mathrm{~km} .(\mathrm{Pl})$

We were confused. We had informed the party that there was a fracture patient and needed evacuation to KKHI. But there was no response as the resource was limited.(P5)

What was difficult was to get wheelchair because the patient could not move himself. The hotel provided only two wheelchair which could be used together at the hotel. When we reported to borrow a wheelchair, it would be okay. But sometimes we needed to wait.(P2)

We face hindrance during caring the patient because we needed to wait for the ambulance. It took longer time for the ambulance to arrive. We were worried, uneasy, concerned about the condition of the pilgrim as got breathing problem and got cold along with sweat.(P3)

\section{DISCUSSION}

\section{Theme: Treating the Pilgrims as Family}

Kendari nurses at a medical team of Indonesia Hajj applied family approach concept to get closer, to reach, and to get access of health services for the pilgrim ( Ministry of Health, 2016). This strategy was done during of the pilgrims health guidance provision at the allocated location. These participants were invovled in the activity of collecting health data of the pilgrims. During the guidance and training of Manasik Hajj, the participants also came to observe directly the condition of high risk pilgrims during Manasik. In the Hajj dormitory, participants lived with the pilgrims. They re-listed health status of the pilgrims and reintroduced themselves as health officers with team which would accompany the pilgrims during Hajj (Wicaksono, 2017).

The step taken by participants to find out and to recognize health characteristics of pilgrim as reference to set up aid and prepare themselves to face emergency state which threatened the pilgrims' safety. It is described as an nurse's role in term of emergency state condition. According to Campo et al., (2016), it includes assessment, diagnosis, categorise the patient based on priority, observation, collaborative action, coordination to ask reference and anticipative action to prevent increasing numbers of victims.
The participants must recognize the causes of emergency states of the pilgrim by assessing internal factor through initial checking, physical condition, general conditoin and health condition, checking vital organs, identifying whether the pilgrims are grouped into $>60$ year old individual with inherited disease such as heart problems, hypertension, upper breathing system infection - asthma, diabetes melitus, and stroke. External factor assessment done by participants are by observing extreme natural conditon, hot temperature, dust, climate differences, sunlights and density of pilgrims (Ministry of Health, 2017). Research done by Pane et al., (2013) explained that emergency state condition and death of the pilgrim during Hajj tends to occur on older pilgrims with various disease history suffered by them.

\section{Theme: Withstanding in Facing Unexpected Condition in Holy Land}

Various conditions and situations threatening health and safety of the pilgrims during Hajj in Mecca must be faced by the participants to guarantee health and safety of the pilgrims. The challenges faced by them are density of pilgrims, traffic jam, geographical condition, extreme climate, contagious disease risk which becomes the highest factor of disease and death in this case (Khan et al., 2017).

Participants' readiness is necessary so that they are able to provide services for the pilgrims efficiently, to prevent any dangerous trauma and other such cases. To withstand this adverse condition, the participants must have strong motivatoin to save the pilgrims. Besides his determination, knowledge, and experience, skills which influence their readiness in facing various conditions is also necessary to anticipated or to face the unexpected. This readiness will be more effective if it is supported by sufficient facilities (Karampourian et al., 2018).

Research by Alaska et al., (2017) explained that Hajj activities involves activity facing highly crowded conditions with various sets of activities going on in the surroundings. It is expected to involve more than three million of pilgrims from all over 180 countries, gathering in Mecca. Such a situation is the main cause of disaster. This activity of pilgrims focused in Mecca for one week is the top agenda of Hajj. The extreme temperature is reported to be the highest trigger of death and injury of the pilgrims during this period (Alaska et al., 2017). The activiteis such as throwing Jumrah, doing tawaf, passing 
tunnel from Mina and other such activities that involve risk of injury and death of the pilgrims due to stampede by the crowd, accident, tiredness, and others.

\section{Facing Heaviest Challenge in Saving Pilgrims}

Being a nurses at a medical team of Indonesia Hajj is not an easy job. To face pilgrims with different characteristics in unfamiliar working area make it difficult for the participants to help and to take care of the pilgrims in emergency conditoin. The safety of the pilgrims is the task and responsibility of the participants. Their duty is not only to protect them from disease but also to put maximum effort to prevent any injury or death. Limited equipment should not stop the participants to give up. They must always think about pilgrims' safety and provide aids to them. The difficuties experienced by them in helping and taking care of pligrim in emergency state condition are caused by insufficient facility. It is important to provide sufficient facility along with readiness of medical workers is necessary to support the teams to provide adequate aids for the pilgrims (Memish et al., 2013).

Limited facilities will hinder the participants to provide maximum aids for pilgrims with emergency state condition. According to, limitation or insufficient supportive facilities influence treatment with delayed aid and assistance provision. Limited equipment and facility will cause burdening load of works and lengthy accomplishing time. This is caused due to greater number of victims, high difficulty, varied cases and limited number of officers (Carigger \& Holcom, 2007).

\section{CONCLUSION AND IMPLICATION}

Facing burdening task to save pilgrims in holy land is not easy situation to guarantee their safety. Participants should face difficult conditoins and situations while accompanying the pilgrims. Withstanding to face unexpected conditions is a readiness embodiment of the participants to prevent accident. Treating the pilgrims as family is used to motivate the participants to provide better service.

The findings can be used as basic training for nurses to prepare themselves as a member of a medical team of Indonesia Hajj and to understand the needs in executing emergency state conditon. For related institutions, it is expected to be used for reference in revising, in improving and preparing services for the pilgrims. Preparation of the pilgrims by implementing istiha'ah of pilgrims' health will help them to maximize their Hajj. Also by recruiting competent health workers and by increasing the facilities these adverse conditions can be improved gradually.

\section{REFERENCES}

Ahmed, Q.A., Arabi, Y.M. \& Memish, Z.A. (2006). Health Risks at the Hajj. Lancet, 367(9515), pp 1008-1015.

Alaska, A.Y., Aldawas, D.A., Aljerian, A.V., Memish, A.Z. \& Suner, S. (2017). The impact of crowd control measures on the occurrence of stampedes during Mass Gatherings: The Hajj experience. Travel Medicine and Infectious Disease, 15, 67e70.

Campo, T.M., Carman, M.J., Evans, D., Hoyt, K.S., Kincaid, K., Ramirez, E.G., Roberts, E., Stackhouse, K., Wilbeck, J. \& Weltge, A. Scope of Practice for Emergency Nurse Practitioners. Advanced Emergency Nursing Journal, 38(4), pp 252-254.

Carigger, J.N. \& Holcom, L. (2007). Practical Strategies for Providing Culturally Sensitive, Ethical Care in Developing Nations. Journal of Transcultural Nursing, 18(1), pp 67-69.

Karampourian, A., Ghomiana, Z. \& Zavareha, K.D. (2018). Qualitative study of health system preparedness for traumatic incidents in a religious mass gathering. International Journal of The Care of The Injured, 50(5), pp 1097-1104.

Khan, D., Khan, A.S., Asima, B., Hussaini, B. S., Zakiuddin, M. \& Faisal, A.F. 2017. Morbidity and mortality amongst Indian Hajj pilgrims: A 3-yearexperience of Indian Hajj medical mission in mass-gathering medicine. Journal of Infection and Public Health, 11(2018), pp 165-170. 
Memish, Z.A., Al-Tawfiq, J.A. \& Al-Rabeeah, A.A. (2013). Hajj: preparations underway. The Lancet Global Health, 1(6): e331

Ministry of Health (2016). Pedoman Umum Program Indonesia Sehal Dengan Pendekatan Keluarga. Jakarta, Kemenkes RI, pp 19-20.

Ministry of Health (2017). Pemeriksaan dan Pembinaan Kesehatan Haji Mencapai Istithaah Kesehatan Jemaah Haji Untuk Menuju Keluarga Sehat (Petunjuk Teknis Permenkes Nomor 15 Tahun 2016). Jakarta, Pusat Kesehatan Haji, pp 18-20.

Pane, M., Imari, S., Alwi, Q., Kanduri, I.N., Cooc, A.R. \& Samaan, G. (2013). Causes of Mortality for Indonesian Hajj Pilgrims: Comparison between Routine Death Certificate and Verbal Autopsy Findings. Plos One, 8(8), e73243.

Pew Research Centre (2011). Sunni and Shia Muslims. Retrived from: https://www. pewforum.org/ 2011/01/27/future-of-the-global-muslim-population-sunni-and-shia/

Smith, J.A., Flowers, P. \& Larkin, M. (2009). Interpretative Phenomenological Analysis: Theory, Method and Research. London: Sage Publications.

Wicaksono, I.Y. (2017). Jurus-Jurus dan Tips-Tips Menjadi TKHI, Sidoarjo. Indomedia Pustaka, pp 42-45. 